УДК 538.9

\title{
ВЛИЯНИЕ ВЫСОКОДИСПЕРСНОЙ СМЕСИ ГЕ/ГЕО НА МЕХАНИЧЕСКИЕ СВОЙСТВА ПОЛИАМИДА
}

Акаева Маднат Магомедовна к.т.н., доцент

ФГБОУ ВО «Чеченский государственный университет»

Аннотация: в данной работе исследовано влияние высокодисперсной смеси $\mathrm{Fe} / \mathrm{FeO}$ на основные физико-механические характеристики композиционных материалов на основе полиамида. Исследованы основные деформационно-прочностные свойства полиамида и композиций на основе полиамида. Показано, что введение $\mathrm{Fe} / \mathrm{FeO}$ в матрицу полиамида приводит к улучшению не только физико - механические свойств, но и химической стойкости.

Ключевые слова: полиамид, композит, агрессивная среда, наполнители, макромолекула.

\section{INFLUENCE OF A HIGH-DISPERSED Fe / FeO MIXTURE ON THE MECHANICAL PROPERTIES OF POLYAMIDE}

\section{Akaeva Madnat Magomedovna}

\begin{abstract}
In this work, the effect of a highly dispersed $\mathrm{Fe} / \mathrm{FeO}$ mixture on the main physical and mechanical characteristics of composite materials based on polyamide is investigated. The main deformation and strength properties of polyamide and compositions based on polyamide have been investigated. It is shown that the introduction of $\mathrm{Fe} / \mathrm{FeO}$ into the polyamide matrix improves not only the physical and mechanical properties, but also the chemical resistance.

Key words: polyamide, compositions, corrosive environments, fillers, a macromolecule.

Производство изделий из полимеров увеличивается в мире с каждым годом. Тем самым заменяя легкоплавкие металлы и сплавы. Благодаря специфическим свойствам полимеры применяются в различных отраслях
\end{abstract}


промышленности. Несомненно, экономическое развитие государства зависит от научно-технического прогресса. Создание и исследование конкурентоспособный конструкционный материал стратегически важно для промышленности. Полимеры

Промышленные полимеры в чистом виде не так часто используют для создания изделий. Часто полимеры модифицируют, в следствии получают полимерный композиционный материал с требуемыми эксплуатационными характеристиками. В связи с этим была попытка получить и исследовать композиционный материал на основе полиамида.

Эксплуатационные возможности полимеров определяют деформационно - прочностные характеристики. Для прогнозирования прочности определяют несколько характеристик. Наиболее исследована напряжение разрушения, при котором происходит разрушение образца. На основании экспериментальных данных возникла молекулярная теория прочности, основанной на изучении физической кинетики процесса разрушения, пришли к выводу, что полимеры могут разрушаться при напряжениях меньше критического напряжения [5].

Изделия из полиамида часто используют в различных агрессивных средах. Агрессивная среда приводит к деструкции полимера изменению структуры и свойств. При жидкой среде основным фактором является гидролитическая деструкция. В макромолекуле наряду с разрывом химических связей идет образование новых химических связей между макромолекулами. Основной механизм приводящим к выходу полимерных изделий и конструкций из строя является гидролитическая деструкция [1, с. 3].

По литературным данным модификация полимера неорганическими наполнителями регулируют свойства композита. Свободный объем матрицы полимера заполняется наполнителем и модифицируют композицию, придавая ей нужные свойства и качества, обусловленные условиями эксплуатации изделий [2, с. 114].

В связи с этим, представляло интерес исследования действий агрессивных сред на модифицированные ПА. В работе были изучены и ПА 6-211ДС и композиционные материалы в концентрациях $\mathrm{Fe} / \mathrm{FeO}$ - 0,05 и 0,1\%. Одну партию стандартных образцов полиамида и КМ выдерживали в течение 120 часов, при температуре 20 - $25{ }^{\circ} \mathrm{C}$ ненапряженном состоянии в соответствии с требованиями ГОСТа $15 \%$-ном водном растворе соляной кислоты, следующие две партии выдерживали $15 \%$ водном растворе гидроксида калия и дистиллированной воде. По истечении времени образцы 
извлекали из жидкой агрессивной среды, промывали и сушили в вакуумной печи в течении 120 мин при температуре $100{ }^{\circ} \mathrm{C}$. Механические свойства: ударная вязкость $\left(\mathrm{A}_{\mathrm{p}}\right)$, разрывное напряжение $\left(\sigma_{\mathrm{p}}\right)$, модуль упругости $\left(\mathrm{E}_{\mathrm{y}}\right)$, разрывное удлинение $\left(\varepsilon_{\mathrm{p}}\right)$ полиамида и композиций определяли по известному методу Шарпи [3, с. 235]. Результаты испытаний полиамида и КМ представлены в таблицах 1, 2.

Таблица 1

Концентрационная зависимость механических свойств ПА и КМ

в процессе экспонирования $72 ч$.

\begin{tabular}{|c|c|c|c|c|c|c|c|c|c|c|c|c|c|}
\hline \multirow{2}{*}{$\begin{array}{l}\text { № } \\
\text { П/ா }\end{array}$} & \multirow{2}{*}{$\begin{array}{c}\text { Oбразе } \\
\text { I } \\
\text { KM }\end{array}$} & \multicolumn{4}{|c|}{$\mathrm{H}_{2} \mathrm{O}$ дистиллированная } & \multicolumn{4}{|c|}{$15 \% \mathrm{KOH}$} & \multicolumn{4}{|c|}{$15 \% \mathrm{HCI}$} \\
\hline & & $\begin{array}{c}\mathrm{Ap}, \\
\text { Дж/M2 }\end{array}$ & $\begin{array}{c}\text { ор, } \\
\text { МПа }\end{array}$ & $\begin{array}{c}\mathrm{E} \\
\text { ГПа }\end{array}$ & $\mathrm{\varepsilon p}, \%$ & $\begin{array}{c}\text { Ap, } \\
\text { Дж/M2 }\end{array}$ & $\begin{array}{l}\text { ор, } \\
\text { МПа }\end{array}$ & $\begin{array}{c}\mathrm{E} \\
\text { ГПа }\end{array}$ & $\varepsilon, \%$ & $\begin{array}{c}\mathrm{Ap}, \\
\text { Дж/M2 }\end{array}$ & $\begin{array}{c}\text { бp, } \\
\text { МПа }\end{array}$ & $\begin{array}{c}\text { E, } \\
\text { ГПа }\end{array}$ & $\varepsilon \mathrm{p}, \%$ \\
\hline 1 & $\begin{array}{c}\text { ПА6- } \\
211 Д С ~ \\
\text { исх }\end{array}$ & 48,72 & 83,55 & 3,51 & 3,65 & 47,75 & 62,2 & 1,35 & 3,13 & 49,77 & 46,09 & 10,11 & 3,21 \\
\hline 2 & \begin{tabular}{|c|} 
ПА6- \\
$211 Д С$ \\
$+0,05(\mathrm{z}$ \\
)
\end{tabular} & 49,31 & 84,16 & 3,37 & 4,89 & 52,13 & 63,71 & 3,1 & 4,19 & 52,81 & 53,39 & 9,15 & \\
\hline 3 & $\begin{array}{c}\text { ПА6- } \\
211 Д \mathrm{C} \\
+0,1(\mathrm{z}) \\
\end{array}$ & 48,31 & 86,04 & 3,01 & 5,9 & 50,01 & 67,2 & 3,09 & 5,2 & 54,79 & 54,13 & 9,17 & 3,23 \\
\hline
\end{tabular}

Таблица 2

Концентрационная зависимость механических свойств ПА и КМ в процессе экспонирования 120 ч.

\begin{tabular}{|c|c|c|c|c|c|c|c|c|c|c|c|c|c|}
\hline \multirow{2}{*}{$\begin{array}{l}\text { № } \\
\Pi / \Pi\end{array}$} & \multirow{2}{*}{$\begin{array}{c}\text { Образе } \\
\text { ц } \\
\text { КМ }\end{array}$} & \multicolumn{4}{|c|}{$\mathrm{H}_{2} \mathrm{O}$ дистиллированная } & \multicolumn{4}{|c|}{$15 \% \mathrm{KOH}$} & \multicolumn{4}{|c|}{$15 \% \mathrm{HCI}$} \\
\hline & & $\begin{array}{c}\mathrm{Ap}, \\
\text { Дж/M2 }\end{array}$ & $\begin{array}{c}\text { ор, } \\
\text { МПа }\end{array}$ & $\begin{array}{c}\text { E, } \\
\Gamma \Pi а\end{array}$ & $\varepsilon p, \%$ & $\begin{array}{c}\mathrm{Ap}, \\
\text { Дж/M2 }\end{array}$ & $\begin{array}{c}\text { ор, } \\
\text { МПа }\end{array}$ & $\begin{array}{c}\text { E, } \\
\Gamma \Pi а\end{array}$ & $\varepsilon, \%$ & $\begin{array}{c}\text { Ap, } \\
\text { Дж/M2 }\end{array}$ & $\begin{array}{c}\text { ор, } \\
\text { МПа }\end{array}$ & $\begin{array}{c}\text { E, } \\
\Gamma П а\end{array}$ & $\varepsilon p, \%$ \\
\hline 1 & $\begin{array}{c}\text { ПА6- } \\
211 \text { ДС } \\
\text { исх } \\
\end{array}$ & 46,31 & 82,94 & 4,45 & 2,32 & 45,21 & 61 & 9,15 & 3 & 48,15 & 45 & 9,01 & 3,1 \\
\hline 2 & $\begin{array}{c}\text { ПА6- } \\
211 \text { ДС } \\
+0,05(\mathrm{z} \\
) \\
\end{array}$ & 47,31 & 83,16 & 1,79 & 4,06 & 52,13 & 47,61 & 9,1 & 3,04 & 51,01 & 52,3 & 9,15 & 3,03 \\
\hline 3 & $\begin{array}{c}\text { ПА6- } \\
211 \text { ДС } \\
+0,1(\mathrm{z}) \\
\end{array}$ & 48,31 & 46,04 & 2,61 & 5,3 & 46,01 & 67,2 & 1,09 & 3,17 & 53,37 & 49,59 & 9,17 & 3,07 \\
\hline
\end{tabular}

z-высокодисперсная смесь $\mathrm{Fe} / \mathrm{FeO}$

Получение полимерного композиционного материала с необходимыми свойствами за счет модификаторов часто решаемая задача. 
Высокомолекулярные и низкомолекулярные вещества химически не совместимы. Оптимально подобрана концентрация добавок т.е концентрационная точка технологической совместимости эффективно влияет на физико-химические свойства композита.

Анализ данных таблиц 1, 2 показывает, что введение $\mathrm{Fe} / \mathrm{FeO}$ в матрицу полимера оказывает влияние на физико-механические характеристики полиамида и полипропилена из чего следует, повышение стойкости КМ к агрессивным средам.

\section{Список литературы}

1. Акаева М.М. Динамика изменения физико - механических свойств полимерных композиций ПБТ - ПЭВП в жидких агрессивных средах. // Вестник ЧГУ. - 2015. - №1. - С. 53-56.

2. Зуев Ю.С. Разрушение полимеров под действием агрессивных сред, М.: Химия. $-1972 .-232$ с.

3. Малкин А.Я., Аскадский А.А., Коврига В.В. Методы измерения механических свойств полимеров, - М.: Химия. - 1978. - 336 с.

4. Пластмассы. Метод определения стойкости к действию химических сред, ГОСТ 12020-72М. - 1979.

5. Перепечко И.И. Введение в физику полимеров, - М.: Химия. - 1978. $312 \mathrm{c}$.

(C) М.М. Акаева, 2020 